\title{
Efeito Residual de Herbicidas Aplicados em Pré-Emergência em DIFERENTES SOLOS ${ }^{1}$
}

\author{
Residual Effect of Herbicides Applied in Pre-Emergence in Different Soils
}

\author{
INOUE, M.H. ${ }^{2}$, SANTANA, C.T.C. ${ }^{3}$, OLIVEIRA JR., R.S. ${ }^{4}$, POSSAMAI, A.C.S. ${ }^{5}$, SANTANA, D.C. ${ }^{3}$, \\ ARRUDA, R.A.D. ${ }^{2}$, DALLACORT, R. ${ }^{2}$ e SZTOLTZ, C.L. ${ }^{2}$
}

\begin{abstract}
RESUMO - O objetivo deste trabalho foi monitorar o efeito residual dos herbicidas ametryne, clomazone e diuron, aplicados em pré-emergência, utilizando amostras de um Neossolo Quartzarênico e de um Latossolo Vermelho, com texturas e composições contrastantes. Para isso, foram conduzidos seis bioensaios em casa de vegetação, com amostras de um Neossolo Quartzarênico (textura arenosa) e de um Latossolo Vermelho (textura argilosa). Foi avaliado o efeito residual de ametryne $\left(0,1,60\right.$ e 2,40 $\left.\mathrm{kg} \mathrm{ha}^{-1}\right)$, clomazone $(0,0,90$ e $\left.1,10 \mathrm{~kg} \mathrm{ha}^{-1}\right)$ e diuron $\left(0,1,60\right.$ e 3,20 $\left.\mathrm{kg} \mathrm{ha}^{-1}\right)$, por meio de semeadura de bioindicador previamente selecionado (Cucumis sativus ou Brachiaria decumbens) aos 0, 25, 50, 75 e 100 dias após a aplicação (DAA). Verificou-se que ametryne proporcionou $80 \%$ de controle até os 40 DAA, independentemente do solo e da dose. O clomazone apresentou efeito residual satisfatório quando aplicado na dose recomendada em solo argiloso, mantendo o controle acima de $80 \%$ até os 71 DAA. Em solo arenoso, o controle não foi satisfatório já aos 25 DAA, mesmo na dose recomendada para solo argiloso. Diuron apresentou alta estabilidade em solo argiloso, observando-se controle superior a 91\% até os 100 DAA na dose recomendada e controle acima de $80 \%$ até os 54 DAA na dose recomendada para solo arenoso. No entanto, em solo arenoso não houve aumento do efeito residual, mesmo com a aplicação da dose recomendada para solo argiloso.
\end{abstract}

Palavras-chave: bioindicadores, herbicidas, persistência, retenção.

\begin{abstract}
The objective of this work was to monitor the residual effect of the herbicides ametryne, clomazone and diuron, applied in pre-emergence, using Psament and Red Latosol with contrasting texture and composition. Thus, six experiments were conducted under greenhouse conditions with samples of Psament (sandy texture) and Red Latosol (clay texture). The residual effect of ametryne $(0,1.60$ and $2.40 \mathrm{~kg} \mathrm{ha-1)}$, clomazone $(0,0.90$ and $1.10 \mathrm{~kg} \mathrm{ha-1)}$ and diuron (O, 1.60 and $3.20 \mathrm{~kg} \mathrm{ha}{ }^{1}$ ) was evaluated by sowing the test plant (Cucumis sativus or Brachiaria decumbens) at $0,25,50,75$ and 100 days after application (DAA). Ametryne was found to provide $80 \%$ control up to $40 \mathrm{DAA}$, independent of type of soil and dose. Clomazone showed satisfactory residual effect when applied at the dose recommended for clay soil, maintaining control over $80 \%$ up to $71 \mathrm{DAA}$. In sandy soil, the control was not satisfactory up to $25 \mathrm{DAA}$, even at doses recommended for clay soil. Diuron showed high stability in clay soil, observing control over $91 \%$ up to 100 DAA at the recommended dose and control over 80\% up to 54 DAA at the dose recommended for sandy soil. However, in sandy soil, no residual effect increase was observed, even when the dose recommended for clay soil was applied.
\end{abstract}

Keywords: bio-indicators, herbicides, persistence, retention.

Recebido para publicação em 29.4.2010 e na forma revisada em 6.5.2011.

2 Dep. de Agronomia, Universidade do Estado de Mato Grosso, Rod. MT 358, Km 07, Caixa Postal 287, 78300-000 Tangará da Serra-MT, Brasil, <miriamhinoue@hotmail.com>; ${ }^{3}$ Pós-Graduação em Agricultura, Universidade Estadual Paulista "Júlio de Mesquita Filho" - Botucatu-SP, Brasil, ${ }^{4}$ Dep. de Agronomia, Universidade Estadual de Maringá - Maringá-PR, Brasil; ${ }^{5}$ Pós-Graduação em Agronomia, Universidade Estadual de Mato Grosso do Sul, Aquidauana-MS.

Planta Daninha, Viçosa-MG, v. 29, n. 2, p. 429-435, 2011 


\section{INTRODUÇÃO}

Pelo grande volume utilizado nos últimos anos, os herbicidas se destacam como defensivos muito importantes na obtenção de alta produtividade em grandes áreas, sendo uma alternativa eficaz e economicamente viável. Mesmo com o aumento da oferta de herbicidas aplicados em pós-emergência, grande parte das aplicações de herbicidas ainda é realizada diretamente no solo, em préemergência ou em pré-plantio incorporado. Com isso, tanto a eficiência no controle de plantas daninhas quanto o destino final no ambiente são controlados pela forma com que as moléculas se comportam no solo. Dependendo da estrutura química e das condições edafoclimáticas, os herbicidas podem não ser completamente degradados durante o ciclo da cultura principal, deixando resíduos com características tóxicas, ou não, à cultura sucessora (Cobbuci \& Machado, 1999).

A intensidade, a época e o efeito residual de herbicidas aplicados no controle de plantas daninhas têm efeito direto e relevante no potencial produtivo das culturas. Esse controle é importante devido à competição das plantas daninhas com as culturas por fatores indispensáveis à expressão de seu potencial produtivo, como água, luz e nutrientes (Durigan et al., 1983; Fleck et al., 1989). Dessa forma, é evidente a necessidade de estratégias eficientes no controle das comunidades infestantes, como a aplicação de herbicidas em pré e pós-emergência, prática bastante comum nos diferentes sistemas produtivos (Maciel et al., 2008).

Ametryne, clomazone e diuron são herbicidas utilizados no controle de plantas daninhas na cana-de-açúcar. São herbicidas mais comumente aplicados em pré-emergência, e a persistência deles varia de acordo com a estrutura química da molécula, o tipo de solo, a umidade do solo e as condições climáticas (Rodrigues \& Almeida, 2005). Segundo Filizola et al. (2002), quando os herbicidas alcançam o solo, dá-se início à degradação desses compostos, a qual pode ser extremamente curta ou perdurar por meses ou anos, no caso de compostos altamente persistentes.

Ametryne é uma molécula do grupo químico das s-triazinas que apresenta propriedades fisico-químicas que lhe conferem elevada persistência no ambiente, podendo permanecer por até seis meses no solo (Rodrigues \& Almeida, 2005). O clomazone pertence ao grupo químico das isoxazolidinonas, grupo este que atua na inibição da biossintese de carotenoides e apresenta persistência no solo por cerca de 100 a 120 dias (Rodrigues \& Almeida, 2005). A meia-vida do clomazone no solo varia de 5 a 117 dias, dependendo do tipo do solo e das condições ambientais (Curran et al., 1992; Mervosh et al., 1995; Kirksey et al., 1996). O diuron é um herbicida do grupo das ureias substituídas, cujo mecanismo de ação é a inibição do fotossistema II e consequente interrupção da fotossintese (Rizzardi et al., 2004). Em solos do Brasil, o diuron é fortemente adsorvido pelos coloides de argila ou matéria orgânica (Inoue et al., 2008) e, por essa razão, a dose adequada é altamente dependente das características do solo (Rodrigues \& Almeida, 2005).

Em decorrência da grande variabilidade das características físicas, químicas e biológicas dos solos do Brasil, pouco se sabe a respeito do comportamento de herbicidas neles, e menos ainda sobre o comportamento de herbicidas em solos do cerrado, os quais podem apresentar grande variabilidade de composição. Portanto, é prioritário estudar os processos que envolvem a atividade residual dessas moléculas nesses solos, onde a disponibilidade de dados é praticamente nula.

Diante da intensa utilização de herbicidas, aliada à escassez de informações referentes ao efeito residual desses compostos no solo, objetivou-se neste trabalho monitorar o efeito residual dos herbicidas ametryne, clomazone e diuron, aplicados em pré-emergência, utilizando solos de diferentes texturas e tipos, por meio de bioensaios.

\section{MATERIAL E MÉTODOS}

Foram realizados seis experimentos na forma de bioensaios em casa de vegetação, com o objetivo de monitorar o efeito residual dos herbicidas ametryne, clomazone e diuron, em diferentes tipos de solos com texturas contrastantes. Para isso, foram utilizadas amostras de solos provenientes de Tangará da Serra (Latossolo Vermelho - LV, textura argilosa) e Campo Novo do Parecis (Neossolo Quartzarênico - RQ, textura arenosa) (Tabela 1). 
Tabela 1 - Características físico-químicas das amostras de solos utilizadas nos experimentos

\begin{tabular}{|c|c|c|c|c|c|c|c|}
\hline \multirow{2}{*}{ Solo } & \multicolumn{2}{|c|}{$\mathrm{pH}$} & $\mathrm{Al}^{3+}$ & $\mathrm{H}^{+}+\mathrm{Al}^{3+}$ & $\mathrm{Ca}^{2+}+\mathrm{Mg}^{2+}$ & $\mathrm{Ca}^{2+}$ & $\mathrm{K}^{+}$ \\
\hline & $\left(\mathrm{CaCl}_{2}\right)$ & $\left(\mathrm{H}_{2} \mathrm{O}\right)$ & \multicolumn{5}{|c|}{$\left(\mathrm{cmol}_{\mathrm{c}} \mathrm{dm}^{-3}\right)$} \\
\hline $\mathrm{RQ}^{\mathbf{1}^{\prime}}$ & 7,1 & 7,8 & 0 & 1,13 & 2,75 & 2,19 & 0,02 \\
\hline $\mathrm{LV}^{2} /$ & 5,8 & 6,7 & 0 & 3,13 & 6,00 & 4,31 & 0,37 \\
\hline $\mathrm{P}$ & \multicolumn{2}{|c|}{$\mathrm{C}$} & CTC & $\mathrm{V}$ & Areia & Silte & Argila \\
\hline$\left(\mathrm{mg} \mathrm{dm}^{-3}\right)$ & \multicolumn{2}{|c|}{$\left(\mathrm{g} \mathrm{dm}^{-3}\right)$} & $\left(\mathrm{cmol}_{\mathrm{c}} \mathrm{dm}^{-3}\right)$ & $(\%)$ & \multicolumn{3}{|c|}{$\left(\mathrm{g} \mathrm{kg}^{-1}\right)$} \\
\hline 46,8 & \multicolumn{2}{|c|}{15} & 3,90 & 71,0 & 908 & 32 & 60 \\
\hline 2,30 & \multicolumn{2}{|c|}{43} & 9,00 & 67,1 & 415 & 147 & 438 \\
\hline
\end{tabular}

${ }^{1 /} \mathrm{RQ}=$ Neossolo Quartzarênico (textura arenosa); ${ }^{2 /} \mathrm{LV}=$ Latossolo Vermelho (textura argilosa). Fonte: Laboratório de Solos Plante Certo, Várzea Grande-MT.

As amostras coletadas foram peneiradas, secas ao ar e acondicionadas em vasos plásticos com capacidade para $5 \mathrm{dm}^{3}$. Em ensaios preliminares (dados não publicados) foi identificada a espécie vegetal com maior sensibilidade a cada herbicida, a qual foi usada para monitorar os resíduos do produto no solo.

Em cada experimento, foram utilizados um herbicida (ametryne, clomazone ou diuron) e um solo (Latossolo Vermelho ou Neossolo Quartzarênico), distribuídos no delineamento em blocos ao acaso e esquema fatorial $3 \times 5$, com quatro repetições. Os fatores estudados foram doses e periodo de tempo entre a aplicação do herbicida e a semeadura do bioindicador. As doses utilizadas referem-se às recomendações em pré-emergência, respectivamente para solos de textura arenosa e argilosa (Rodrigues \& Almeida, 2005), aplicadas em ambos os solos, além da testemunha sem aplicação de herbicidas. Os períodos referemse à época de semeadura do bioindicador, aos 0, 25, 50, 75 e 100 dias após a aplicação (DAA) dos herbicidas.

As aplicações dos herbicidas ametryne $\left(0,1,60\right.$ e $\left.2,40 \mathrm{~kg} \mathrm{ha}^{-1}\right)$, clomazone $(0,0,90$ e $\left.1,10 \mathrm{~kg} \mathrm{ha}^{-1}\right)$ e diuron (0, 1,60 e 3,20 $\left.\mathrm{kg} \mathrm{ha}^{-1}\right)$ foram feitas de tal forma que a barra do pulverizador estivesse posicionada a $0,5 \mathrm{~m}$ acima da borda superior dos vasos. Todas as aplicações foram realizadas com temperaturas inferiores a $35^{\circ} \mathrm{C}$ e umidade relativa superior a $60 \%$, com auxílio de um pulverizador costal pressurizado $\mathrm{CCO}_{2}$, munido de bicos tipo leque XR110.02, com pressão de trabalho de $2 \mathrm{kgf} \mathrm{cm}^{-2}$, resultando em volume de calda de $200 \mathrm{~L} \mathrm{ha}^{-1}$.
Após a aplicação dos herbicidas, 10 sementes do bioindicador selecionado (Cucumis sativus ou Brachiaria decumbens) foram semeadas aos 0, 25, 50, 75 e 100 DAA, na profundidade de $1 \mathrm{~cm}$. Após a semeadura, os vasos foram mantidos com irrigação diária até 45 dias após a semeadura. Decorrido esse prazo, as partes aéreas das plantas bioindicadoras foram coletadas e colocadas em sacos de papel, levando-as à estufa de ventilação forçada a $40^{\circ} \mathrm{C}$, até massa constante, visando à determinação da matéria seca delas.

Os dados foram transformados para porcentagem de inibição do acúmulo de matéria seca em relação à testemunha (dose de $0 \mathrm{~kg} \mathrm{ha}^{-1}$ ) e submetidos à análise de variância; posteriormente, foram ajustadas equações de regressão $(p>0,05)$. Na análise dos dados foi utilizado o programa Sistema para Análise de Variância (Ferreira, 2003).

\section{RESULTADOS E DISCUSSÃO}

\section{Ametryne}

A Figura 1 apresenta o acúmulo de matéria seca em plantas de $C$. sativus após a aplicação de 1,60 e 2,40 $\mathrm{kg} \mathrm{ha}^{-1}$ de ametryne nas amostras de Latossolo Vermelho e Neossolo Quartzarênico. Independentemente do solo, verificou-se que o herbicida ametryne, nas duas doses avaliadas, proporcionou até os 40 DAA controle acima de $80 \%$, diminuindo gradativamente após esse período. Monquero et al. (2008a) também observaram controle eficiente de Sorghum bicolor até os 40 DAA com a aplicação da mistura ametryne + clomazone 
em Latossolo Vermelho distroférrico (36 $\mathrm{g} \mathrm{dm}^{-3}$ de matéria orgânica - MO e $15 \%$ de argila) e em Latossolo Vermelho distrófico $\left(22 \mathrm{~g} \mathrm{dm}^{-3} \mathrm{de}\right.$ MO e $51 \%$ de argila). Dados semelhantes também foram constatados com o uso de trifloxysulfuron-sodium + ametryne em Latossolo Vermelho distrófico $\left(22 \mathrm{~g} \mathrm{dm}^{-3} \mathrm{de} \mathrm{MO}\right.$ e $51 \%$ de argila) e Latossolo Vermelho distroférrico ( $36 \mathrm{~g} \mathrm{dm}^{-3}$ de $\mathrm{MO}$ e $15 \%$ de argila), mantendo efeito residual estável até os 40 dias de seca após a aplicação (Monquero et al., 2008b). Embora a avaliação do efeito residual de herbicidas no campo esteja sujeita a vários fatores não controlados, como o clima e novos fluxos de germinação, os dados obtidos com o bioensaio parecem ser semelhantes aos verificados em campo.

Analisando-se o efeito da dose em cada solo, o ametryne proporcionou $70 \%$ de controle no Latossolo Vermelho distroférrico até 70 DAA (Figura 1), com a dose recomendada (Rodrigues \& Almeida, 2005). No entanto, com o uso da dose indicada em solos arenosos $\left(1,60 \mathrm{~kg} \mathrm{ha}^{-1}\right)$, o controle no solo argiloso foi de

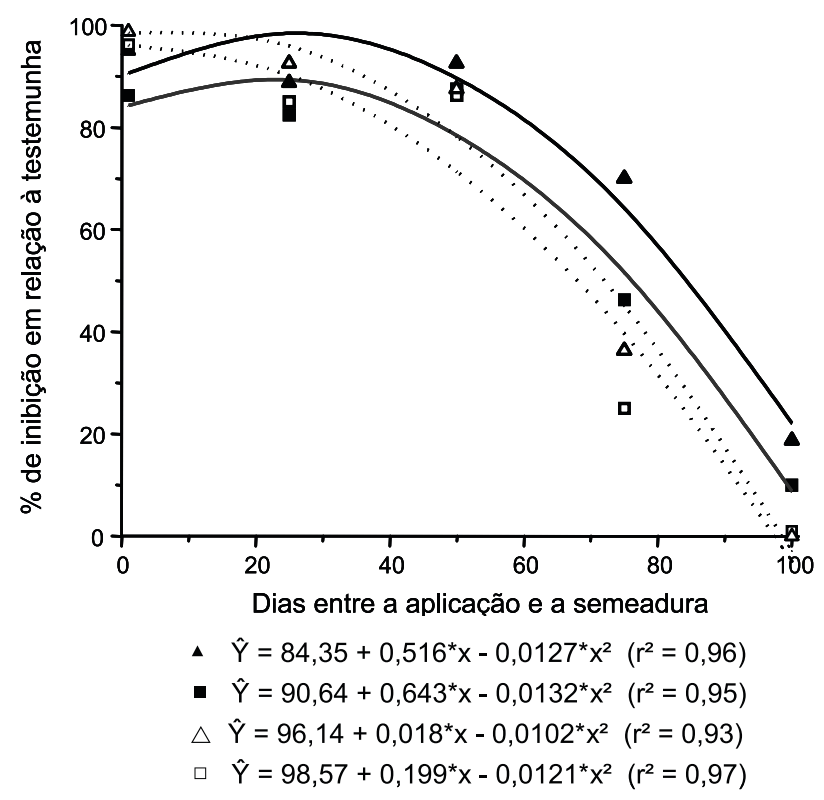

Figura 1 - Porcentagem de inibição no acúmulo de matéria seca de C. sativus, em relação à testemunha, aos $0,25,50,75$ e 100 dias após a aplicação de ametryne, cultivada em amostras de Latossolo Vermelho e Neossolo Quartzarênico. Os triângulos equivalem aos dados observados na dose de $2,40 \mathrm{~kg} \mathrm{ha}^{-1}$, e os quadrados, na dose de 1,60 $\mathrm{kg} \mathrm{ha}^{-1}$. Símbolos sólidos e linhas cheias equivalem aos dados do Latossolo Vermelho, e símbolos vazios e linhas tracejadas, aos do Neossolo Quartzarênico.
$58 \%$ nesse período. Por outro lado, aos 75 DAA o controle não ultrapassou $40 \%$ em ambas as doses avaliadas no solo arenoso (Figura 1). Silva et al. (2002) observaram que ametryne aplicado em pós-emergência (nas doses de 2,50 e 3,75 $\mathrm{kg} \mathrm{ha}^{-1}$ ) em Podzólico VermelhoAmarelo câmbico, textura franco-argiloarenosa $(2,11 \%$ de $\mathrm{MO}$ e $34 \%$ de argila), propiciou controle acima de 90\% em Brachiaria decumbens. No entanto, na dose de $1,25 \mathrm{~kg} \mathrm{ha}^{-1}$ o controle foi de 60 a $70 \%$, não sendo observada reinfestação dessa espécie até 90 DAA. Os autores atribuíram esse resultado ao efeito residual do herbicida, juntamente com o sombreamento da capineira, que, aos 60 DAA, apresentava altura superior a $0,90 \mathrm{~m}$ e intenso fechamento do dossel. Essa persistência pode estar relacionada também com o baixo teor de matéria orgânica e nível de pH. Em trabalhos realizados em solos arenosos da província de Buenos Aires (Argentina), atrazine apresentou persistência de $78 \mathrm{DAA}$ em solos com $\mathrm{pH}$ de 5,8 e $5,5 \%$ de $\mathrm{MO}$ e de 130 DAA em solos com pH de 6,7 e 2,9\% de MO, na dose recomendada (Fuscaldo et al., 1999).

No solo arenoso, o controle se manteve em torno de $80 \%$ até os 40 DAA, nas duas doses avaliadas (Figura 1). Isso indica que o incremento da dose em solos arenosos não aumenta o efeito residual do produto, o que também foi observado em trabalhos anteriores conduzidos por Inoue et al. (2009) com diuron, imazapic e isoxaflutole. A diminuição do efeito residual também está possivelmente relacionada à lixiviação do herbicida, conforme relatado por Vivian et al. (2007). Estes autores quantificaram ametryne nas profundidades de 0,10 e 0,20 m em Argissolo Vermelho-Amarelo eutrófico (1,19 a $1,58 \%$ de MO e 29 a $39 \%$ de argila), enfatizando os riscos de lixiviação desse herbicida na contaminação de águas subterrâneas. Apesar de ter permanecido abaixo dos niveis residuais máximos estabelecidos pela agência internacional de controle ambiental, Lanchote et al. (2000) detectaram resíduos de ametryne na maioria das amostras de água subsuperficial coletadas em áreas de cultivo de canade-açúcar.

Segundo Prata et al. (2001), o aumento da permanência de ametryne no solo ocorre pela baixa porcentagem de mineralização, juntamente com o fato de ele não ser metabolizado 
e não formar resíduo ligado, demandando atenção no comportamento dessa molécula em relação a prováveis problemas ambientais. No entanto, estudos realizados por Andréa et al. (1997) para verificar a influência da temperatura sobre a dissipação de atrazine em solo brasileiro constataram que, independentemente da temperatura, a disponibilidade da molécula na solução do solo só diminui com o tempo.

\section{Clomazone}

Os resultados de inibição no acúmulo de matéria seca de $B$. decumbens com a aplicação de clomazone $\left(0,90\right.$ e $\left.1,10 \mathrm{~kg} \mathrm{ha}^{-1}\right)$ nas amostras de Neossolo Quartzarênico e Latossolo Vermelho podem ser observados na Figura 2.

O clomazone aplicado no Latossolo Vermelho distroférrico de textura argilosa (43 $\mathrm{g} \mathrm{dm}^{-3}$ de $\mathrm{MO}$ e 43,8\% de argila) proporcionou controle do bioindicador acima de $80 \%$ até os 39 DAA, em ambas as doses (Figura 2). No entanto, à medida que se aumentou o período de tempo entre a aplicação e a semeadura das plantas bioindicadoras, observou-se redução no efeito do herbicida no solo argiloso, com controle abaixo de $40 \%$ a partir dos 83 DAA na dose recomendada para solo arenoso $\left(0,9 \mathrm{~kg} \mathrm{ha}^{-1}\right)$. Contudo, a dose recomendada $\left(1,10 \mathrm{~kg} \mathrm{ha}^{-1}\right)$ proporcionou controle acima de $80 \%$ até os 71 DAA. Resultados de Monquero et al. (2008b) permitiram concluir que a aplicação de clomazone + ametryne $(1,50+$ $1,00 \mathrm{~kg} \mathrm{ha}^{-1}$ ) proporciona maior efeito residual em solos com maior teor de argila e matéria orgânica. Trabalhos realizados por Santos et al. (2003) indicaram que o clomazone aplicado na cultura da soja afetou culturas sucessivas de trigo, aveia e cevada devido à sua persistência no solo, o que demanda um intervalo mínimo de 150 DAA para implantação da cultura subsequente.

No solo de textura arenosa, o controle ficou acima de $80 \%$ somente até os 21 DAA, independentemente da dose aplicada. Mervosh et al. (1995) e Senseman (2007) relataram que a persistência do clomazone é menor em solos arenosos do que em solos argilosos - isso explica o comportamento do herbicida nas amostras do RQ, mesmo em doses mais elevadas.
Aos 55 DAA, observou-se que o clomazone proporcionou controle de $B$. decumbens inferior a $50 \%$ no solo de textura arenosa nas doses avaliadas. Canossa (2007) observou que clomazone $\left(1,00 \mathrm{~kg} \mathrm{ha}^{-1}\right)$ aplicado em solo de textura arenosa $\left(7,36 \mathrm{~g} \mathrm{dm}^{-3}\right.$ de MO e $3 \%$ de argila) apresentou, até os 28 DAA, alta capacidade de controle de Alternanthera tenella (<99\%).

No RQ, observa-se também que o herbicida não proporcionou o controle mínimo aceitável (80\%) além dos 28 DAA. Rodrigues \& Almeida (2005) relatam que o clomazone possui meiavida de 15 a 40 dias, dependendo de clima e de solo.

\section{Diuron}

Os resultados de inibição no acúmulo de matéria seca de $B$. decumbens com o uso de diuron aplicado em solo argiloso e solo arenoso são apresentados na Figura 3.

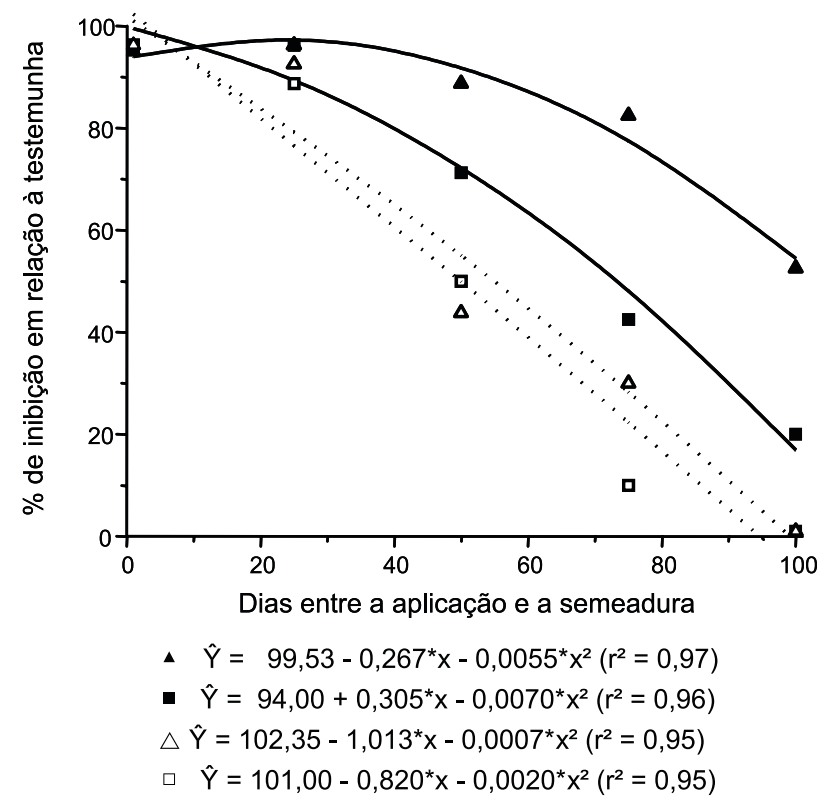

Figura 2 - Porcentagem de inibição no acúmulo de matéria seca de $B$. decumbens, em relação à testemunha, aos $0,25,50,75$ e 100 dias após a aplicação de clomazone, cultivada em amostras de Latossolo Vermelho e Neossolo Quartzarênico. Os triângulos equivalem aos dados observados na dose de $1,10 \mathrm{~kg} \mathrm{ha}^{-1}$, e os quadrados, na dose de $0,90 \mathrm{~kg} \mathrm{ha}^{-1}$. Símbolos sólidos e linhas cheias equivalem aos dados do Latossolo Vermelho, e símbolos vazios e linhas tracejadas, aos do Neossolo Quartzarênico.

Planta Daninha, Viçosa-MG, v. 29, n. 2, p. 429-435, 2011 
O diuron aplicado no solo argiloso até 22 DAA proporcionou excelente controle (acima de 90\%) na menor dose $\left(1,60 \mathrm{~kg} \mathrm{ha}^{-1}\right)$. Nas amostras de textura arenosa, esse herbicida também proporcionou controle até os 10 e 17 DAA, com a utilização das doses recomendadas de 1,60 e 3,20 $\mathrm{kg} \mathrm{ha}^{-1}$ (Figura 3).

Observando os dados relativos às doses de diuron dentro de cada solo, nota-se que o herbicida proporcionou excelente controle (acima de 90\%) no solo argiloso com o uso da dose recomendada, até os 100 DAA (Figura 3). Com a dose recomendada para solo arenoso $\left(1,60 \mathrm{~kg} \mathrm{ha}^{-1}\right)$, a porcentagem de controle esteve acima de $80 \%$ até os 54 DAA. Esses dados indicam que é possivel obter controle satisfatório das plantas bioindicadoras com a utilização de doses menores. Resultados semelhantes são relatados por PeñaherreraColina et al. (2005), em que o diuron proporcionou acentuada redução na produção de matéria seca da parte aérea de Avena sativa aos 10, 20, 30 e 40 DAA do herbicida.

No solo arenoso, o controle se manteve acima dos $80 \%$ apenas até os 18 DAA, tanto com a dose recomendada $\left(1,6 \mathrm{~kg} \mathrm{ha}^{-1}\right)$ quanto na dose utilizada em solo argiloso $\left(2,4 \mathrm{~kg} \mathrm{ha}^{-1}\right)$. Inoue et al. (2008) observaram que em solos de textura mais argilosa a persistência de diuron no solo pode ser maior do que nos de textura arenosa, visto que as moléculas retidas tornam-se menos disponiveis às plantas e aos microrganismos. No entanto, a sorção do diuron - e consequentemente a sua lixiviação - é governada principalmente pela fração orgânica do solo (Prata et al., 2001), podendo ocorrer lixiviação moderável em solos arenosos que apresentam baixo teor de argila e matéria orgânica. Esse fato pode inclusive tornar o herbicida mais eficiente, movendo-o da superficie do solo para onde estão concentradas as sementes de plantas daninhas (Oliveira, 2001).

Com base nos resultados, foi possivel verificar que o comportamento do ametryne foi semelhante em diferentes doses e solos. No entanto, clomazone apresentou maior efeito residual com a dose recomendada em solo argiloso. Há, ainda, a possibilidade de se trabalhar com doses menores de diuron em solos argilosos, sem reduzir o efeito residual. De modo geral, o incremento de doses de herbicidas em solo arenoso não aumentou

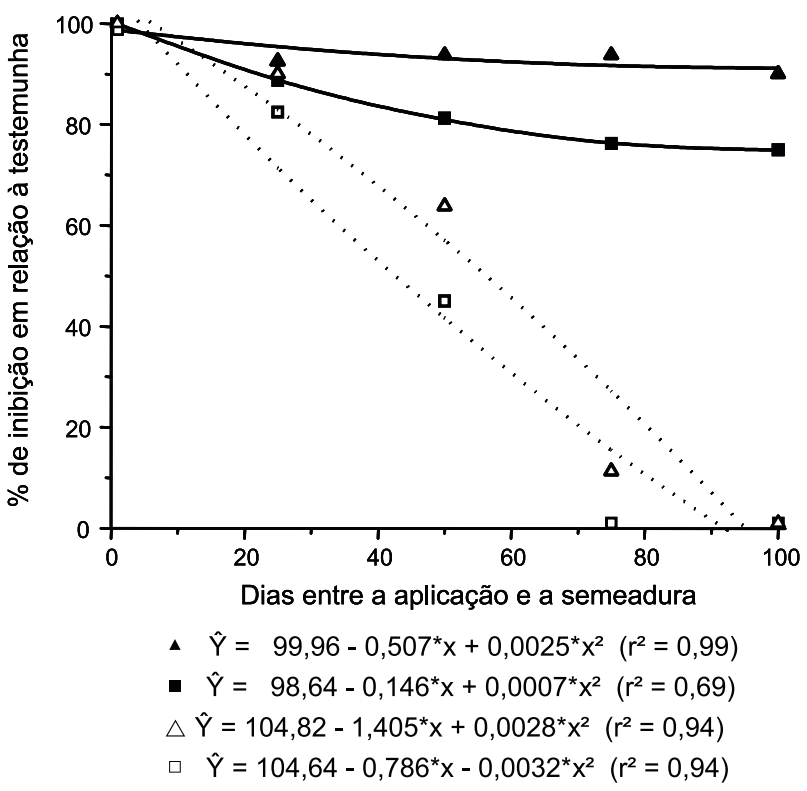

Figura 3 - Porcentagem de inibição no acúmulo de matéria seca de $B$. decumbens, em relação à testemunha, aos 0 , $25,50,75$ e 100 dias após a aplicação de diuron, cultivada em amostras de Latossolo Vermelho e Neossolo Quartzarênico. Os triângulos equivalem aos dados observados na dose de $3,20 \mathrm{~kg} \mathrm{ha}^{-1}$, e os quadrados, na dose de $1,60 \mathrm{~kg} \mathrm{ha}^{-1}$. Símbolos sólidos e linhas cheias equivalem aos dados do Latossolo Vermelho, e símbolos vazios e linhas tracejadas, aos do Neossolo Quartzarênico.

significativamente a atividade residual dos três herbicidas avaliados.

\section{AGRADECIMENTOS}

Os autores agradecem à FAPEMAT e ao CNPq o auxílio financeiro.

\section{LITERATURA CITADA}

ANDRÉA, M. M. et al. Effect of temperature on dissipation of $\left[{ }^{14} \mathrm{C}\right]$-atrazine in a Brazilian soil. Pesq. Agropec. Bras., v. 32, n. 1, p. 95-100, 1997.

CANOSSA R. S. Requisitos para germinação e emergência de apaga-fogo (Alternanthera tenella colla) e alternativas de controle químico. 2007. 57 f. Dissertação (Mestrado em Produção Vegetal) - Universidade Estadual de Maringá, Maringá, 2007.

COBBUCI, T:; MACHADO, E. Seletividade, eficiência de controle de plantas daninhas e persistência no solo de imazamox aplicado na cultura do feijoeiro. Planta Daninha, v. 17, n. 3, p. 419-432, 1999 
CURRAN, W. S.; LIEBL, R. A.; SIMMONS, F. W. Effects of tillage and application methods on clomazone, imazaquin, and imazethapyr persistence. Weed Sci., v. 40, p. 482-489, 1992.

DURIGAN, J. C. et al. Períodos de matocompetição na cultura da soja (Glycine max (L.) Merrill), cultivares Santa Rosa e IAC-2.1 - Efeitos sobre os parâmetros de produção. Planta Daninha, v. 2, n. 1, p. 86-100, 1983.

FLECK, N. G.; MENGARDA, I. P.; PINTO, J. J. O. Interferência de plantas daninhas na cultura de girassol. Competição no tempo. Pesq. Agropec. Bras., v. 24, n. 9, p. $1139-1147,1989$.

FERREIRA, D. F. Programa Sisvar.exe: Sistema de Análise de Variância. Versão 3.04. Lavras: Universidade Federal de Lavras, 2003.

FILIZOLA, H. F. et al. Monitoramento e avaliação do risco de contaminação por pesticidas em água superficial e subterrânea na região de Guairá. Pesq. Agropec. Bras., v. 37, n. 5, p. 659-667, 2002.

FUSCALDO, F.; BEDMAR, F.; MONTERUBBIANESI, G. Persistence of atrazine, metribuzin and simazine herbicides in two soils. Pesq. Agropec. Bras., v. 34, n. 11, p. 2037-2044, 1999.

INOUE, M. H. et al. Lixiviação e degradação de diuron em dois solos de textura contrastante. Acta Sci. Agron., v. 30, p. 631-638, 2008.

INOUE, M. H. et al. Bioavailability of diuron, imazapic and isoxaflutole in soils of contrasting textures. J. Environ. Sci. Health, Part B, v. 44, n. 8, p. 757-763, 2009.

KIRKSEY, K. B. et al. Clomazone dissipation in two Tennessee soils. Weed Sci., v. 44, n. 4, p. 959-963, 1996.

LANCHOTE, V. et al. HPLC screening and GC-MS confirmation of triazine herbicides residues in drinking water from sugar cane area in Brazil. Water Air Soil Poll., v. 118, p. $329-337,2000$.

MACIEL, C. D. G. et al. Eficiência e seletividade dos herbicidas trifloxysulfuron-sodium + ametryne e hexazinone + diuron em função da tecnologia de aplicação e do manejo mecânico da palha de cana-de-açúcar na linha de plantio. Planta Daninha, v. 26, n. 3, p. 665-676, 2008.
MERVOSH, T. L. et al. Clomazone fate as affected by microbial activity, temperature, and soil moisture. J. Agric. Food Chem., v. 43, p. 537-543, 1995.

MONQUERO, P. A. et al. Mobilidade e persistência de herbicidas aplicados em pré-emergência em diferentes solos. Planta Daninha, v. 26, n. 1, p. 411-417, 2008a.

MONQUERO, P. A. et al. Eficiência de herbicidas préemergentes após períodos de seca. Planta Daninha, v. 26, n. 1, p. 185-193, 2008 b.

OLIVEIRA, M. F. Comportamento de herbicidas no ambiente. In: OLIVEIRA JR., R. S.; CONSTANTIN, J. (Eds.). Plantas daninhas e seu manejo. Guaíba: Agropecuária, 2001. p. 315-362.

PEÑAHERRERA-COLINA, L. A. et al. Persistência biológica de ametryn, diuron e oxyfluorfen no solo. Ci. Agrotecnol., v. 29, n. 5, p. 980-987, 2005.

PRATA, F. et al. Degradação e sorção de ametrina em dois solos com aplicação de vinhaça. Pesq. Agropec. Bras., v. 36, n. 7, p. 975-981, 2001.

RIZZARDI, M. A. et al. Aspectos gerais do controle de plantas. In: VARGAS, L.; ROMAN, E. S. Manual de manejo e controle de plantas daninhas. Bento Gonçalves: Embrapa Uva e Vinho, 2004. p. 105-144.

RODRIGUES, B. N.; ALMEIDA, F. S. Guia de herbicidas. 5.ed. Londrina: Edição dos Autores, 2005.

SANTOS, R. L. B.; SPEHAR, C. R.; VIVALDI, L. Quinoa (Chenopodium quinoa) reaction to herbicide residue in a Brazilian Savannah soil. Pesq. Agropec. Bras., v. 38, n. 6, p. 771-776, 2003.

SENSEMAN, S. A. (Ed.). Herbicide handbook. 9.ed. Lawrence: Weed Science Society of America, 2007.

SILVA, W. et al. Redução da interferência de Brachiaria decumbens na formação de pastagem com Penisetum purpureum através de herbicidas. Planta Daninha, v. 20, n. 2, p. 273-281, 2002.

VIVIAN, R. et al. Persistência e lixiviação de ametryn e trifloxysulfluron-sodium em solo cultivado com cana-deaçúcar. Planta Daninha, v. 25, n. 1, p. 111-114, 2007. 